\title{
Intravenous Bolus
}

National Cancer Institute

\section{Source}

National Cancer Institute. Intravenous Bolus. NCI Thesaurus. Code C38274.

A volume of drug intended to be administered into a vein at a relatively fast rate. The volume of drug and the rate of administration are specified. 